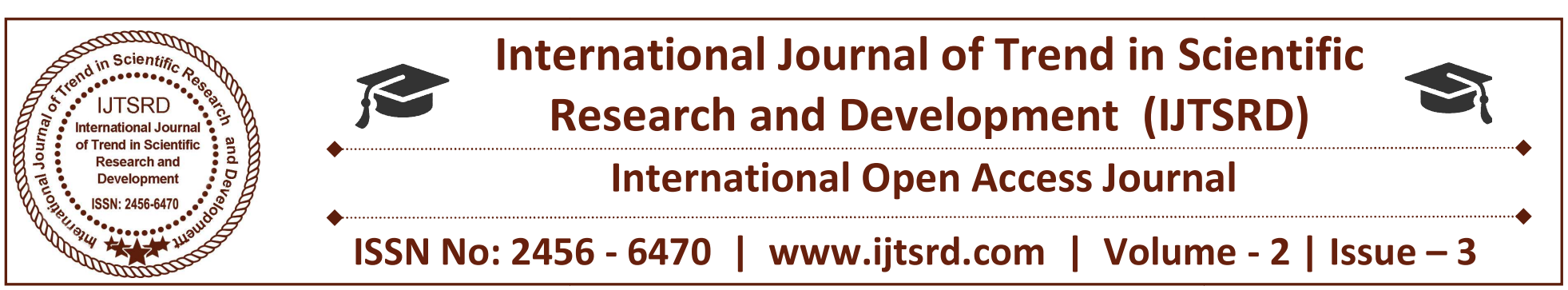

\title{
Different topologies and sizing techniques in PV- Wind-Battery based power system
}

\author{
Akhter Hussain Shah \\ M.Tech Scholar, Electrical Engineering Department, \\ YIET, Gadhauli, Yamunanagar, Haryana, India
}

\begin{abstract}
Uneconomical extension of the grid has led to generation of electric power at the end user facility and has been proved to be cost effective and to an extent efficient. With augmented significance on ecofriendly technologies the use of renewable energy sources such as micro-hydro, wind, solar, biomass and biogas is being explored. This paper presents an extensive review on various topologies and sizing techniques related to Renewable Energy System (RES) based power generation. As solar and wind power is intermittent and unpredictable in nature, higher penetration of their types in existing power system could cause and create high technical challenges especially to weak grids or stand-alone systems without proper and enough storage capacity. The paper also gives a review of the main research work reported in the literature with regard to optimal sizing design, power electronics topologies and control.
\end{abstract}

\section{INTRODUCTION}

Requirement of energy in its most suitable form is the need of millions of people throughout the globe. It can be fuel, used in transportation, electrical energy for lighting loads, etc. With the beginning of $21 \mathrm{st}$ century, industrialization has raised many folds compared to 18th century; this has resulted in a massive scale extraction of fossil fuels at an alarming pace globally. The global climate change has added to the problem of scarcity of fossil fuels. Now it is time to look into the solution of energy crisis, created by the reduction of fossil fuels without altering the climate behavior. In stand-alone mode, transportation of conventional energy sources (like coal, oil, and natural gas) is quite difficult and grid extension is also not cost effective due to remoteness and difficult terrain. Renewable energy is the most appropriate solution to supply energy in isolated areas. Utilization of locally available resources is the best possible option to meet the energy requirement. Depending on the site conditions, single technology or aggregated technology would be selected in stand-alone mode.

Single technology based system (solar photovoltaic/wind/small hydro) is a viable option to supply energy in isolated areas. Un-electrified rural areas like village hamlets or small villages that are far away from the utility grid can be electrified by single technology. In plane remote areas, possible schemes are solar photovoltaic based system, wind energy system etc. Biomass gasifier/biogas based system are suitable for forest remote areas and battery based scheme is appropriate for remote hilly regions. Presently, rooftop solar photovoltaic systems are popular in urban areas to meet out energy demand of a building. Renewable energy resources are highly sitespecific and intermittent in nature as some of the energy sources are available in abundance during winter and others during summer. Therefore, as demand increases in stand-alone mode, single technology based system are associated with high system cost and low reliability. In order to deal with such limitations of single technology based system, the concept of Integrated Renewable Energy System (IRES) has been evolved for power generation in stand-alone applications [1].

Integrated Renewable Energy System (IRES) has been proposed by various researchers to electrify 
remote areas [2-6]. In IRES, energy demand of a remote area is met by using energy potential of locally available renewable energy sources. In this technology, renewable energy sources like solar, wind, Micro Hydro Power (MHP), biomass, biogas etc. can be considered for power generation. IRES have the potential to aggregate benefits such as energy efficiency and energy conservation, resulting from the combination of renewable energy sources. Integrated use of different renewable energy resources minimizes energy storage requirement, increases reliability of power supply and quality of power. For stand-alone applications, these systems are always incorporated with storage devices in order to manage the stochastic behavior of renewable energy sources like solar and wind. Wind-solar-battery based integrated system is shown in Fig. 1. Control system is the heart of IRES that provides the information and communication among various components of system. Control system regulates the output of renewable energy sources and also, generates the signals for scheduling of storage subsystem and dump load. It protects the storage system from overcharging and it help to operate the storage system in prescribed limit. Whenever surplus energy is available, it is sent to storage subsystem to store the surplus energy and if storage system if fully charged, it is wasted in dump load that can be utilized in cooking, water heating, baking etc. Under condition when demand exceeds generation, stored energy is used in order to fulfill deficit load demand.

Some remote places have not sufficient availability of renewable energy resources, under such conditions it is required to add some conventional option like diesel/petrol/gasoline based generator, along with renewable energy resources to fulfill load demand. As diesel generator based integrated system pollutes the environment, it is therefore analysis of greenhouse gas emission level must be carried out. This scheme is not appropriate for hilly terrain and remote areas as problems associated with transportation of fuel.

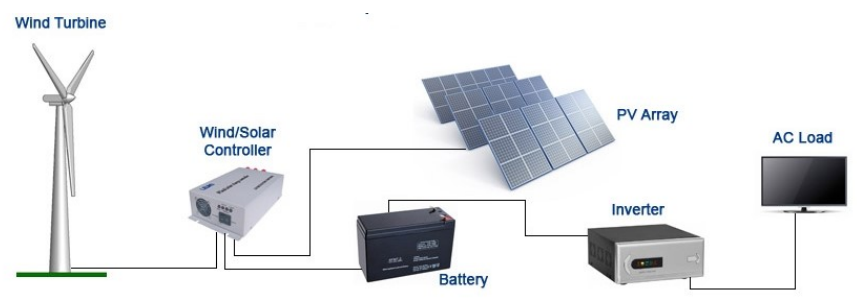

Fig. 1. Schematic of wind-solar-battery based integrated system
This paper provides a review of challenges and opportunities for hybrid system of solar PV and wind. The paper reviews the main research works related to optimal sizing design, power electronics topologies and control for both grid-connected, stand-alone hybrid solar and wind systems incorporating battery energy storage.

\section{HYBRID SOLAR-PV-WIND-BATTERY SYSTEM}

Hybrid solar-wind-battery generation system become very attractive solution in particular for stand-alone applications. Combining the two sources of solar and wind can provide better reliability with battery as a storage and their hybrid system becomes more economical to run since the weakness of one system can be complemented by the strength of the other one. The integration of hybrid solar and wind power systems into the grid can further help in improving the overall economy and reliability of renewable power generation to supply its load. Similarly, the integration of hybrid solar and wind power in a standalone system can reduce the size of energy storage needed to supply continuous power.

Solar electricity generation systems use either photovoltaic or concentrated solar power. The focus in this paper will be on the photovoltaic type. Detailed descriptions of the different technologies, physics and basics of PV can be found in many textbooks and papers such as [4-7]. Kurtz [8] pointed out that ten years ago the concentrator cell was only $\sim 30 \%$ efficient compared with more than $40 \%$ today with the potential to approach $50 \%$ in the coming years. Si cells have efficiencies of $26 \%$ and multi-junction III$\mathrm{V}$-compound cells have efficiencies above 45\% (48\% in the laboratory) as pointed out in reference [9]. PV modules produce outputs that are determined mainly by the level of incident radiation. As the light intensity increases, photocurrent will be increased and the open-circuit voltage will be reduced [10]. The efficiency of any photovoltaic cell decreases with the increasing temperature which is non-uniformly distributed across the cell [11]. The solar output power can be smoothed by the distribution of solar power in different geographical areas [12].

Electricity from solar PV and concentrated solar power plants is significantly expensive and requires significant drop in cost or change in policies by either subsidizing or forcing the use of these technologies to be able to achieve significant market penetration [13]. 
Global wind report (2017) indicated that the annual market grew by around $10 \%$ to reach around 401.5 $\mathrm{GW}$ and the cumulative market growth was almost $31 \%$ [14]. Detailed descriptions of the wind energy can be found in references [4] and [15]. Wind turbines (WTs) are classified into two types: horizontal-axis WT (HAWT) and vertical-axis WT (VAWT). The highest achievable extraction of power by a WT is $59 \%$ of the total theoretical wind power [15].

Hybrid solar-wind systems can be classified into two types: grid connected and stand-alone. Literature reviews for hybrid grid connected and stand-alone solar PV and wind energies were conducted worldwide by many researchers who have presented various challenges and proposed several possible solutions. Due to the nature of hybrid solar PV and wind energies, optimization techniques can play a good role in utilizing them efficiently. Graphic construction methods [16], linear programming [1718], and probabilistic approach [19] are few examples of optimization techniques that have been developed for techno-economically optimum hybrid renewable energy system for both types. Luna-Rubio et al. [20] conducted a review of existing research of optimal sizing of renewable hybrids energy systems with energy storage components for both stand-alone and grid-connected systems. The authors gave brief descriptions about those indicators and the different sizing methods. A review of control strategies for a hybrid renewable energy system was carried out in [21] and another review was done in [22] for optimization of hybrid renewable energy system with more focus on wind and solar PV systems. The reviews in [21] and [22] are applicable for both types; grid-connected and stand-alone systems.

\section{DIFFERENT TOPOLOGIES OF SOLAR- WIND-BATTERY BASED SYSTEM}

Several network interfacing topologies can be found in the literature, which are distinguished by the connection with the utility grid or the structure of the inner current conversion stages. As it can be observed at Fig. 2, two main groups can be identified for the interface devices placed between the ac, dc and the utility network: coupled ac and decoupled ac configurations.

At coupled ac topologies the ac network of the microgrid is directly connected to the power grid by a transformer and an ac-dc converter is used for the dc network. Alternatively, decoupled ac configurations are composed at least by an ac-dc and dc-ac stage; this means there is no direct connection between the power grid and the ac network of the microgrid. Fig. 3 shows the most important configurations identified for both topologies.

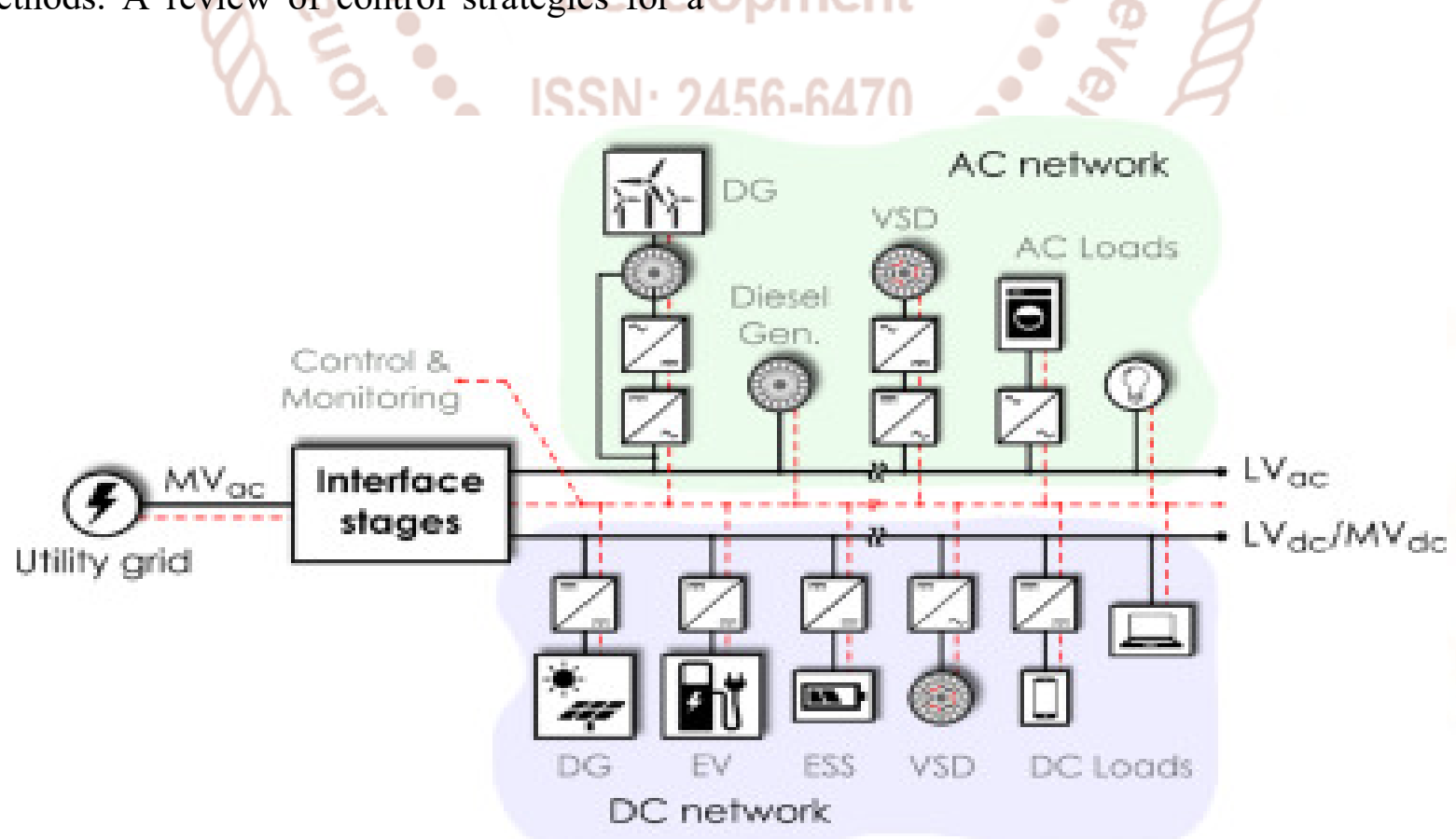

Fig. 1. Example of a hybrid microgrid interfacing topology. 


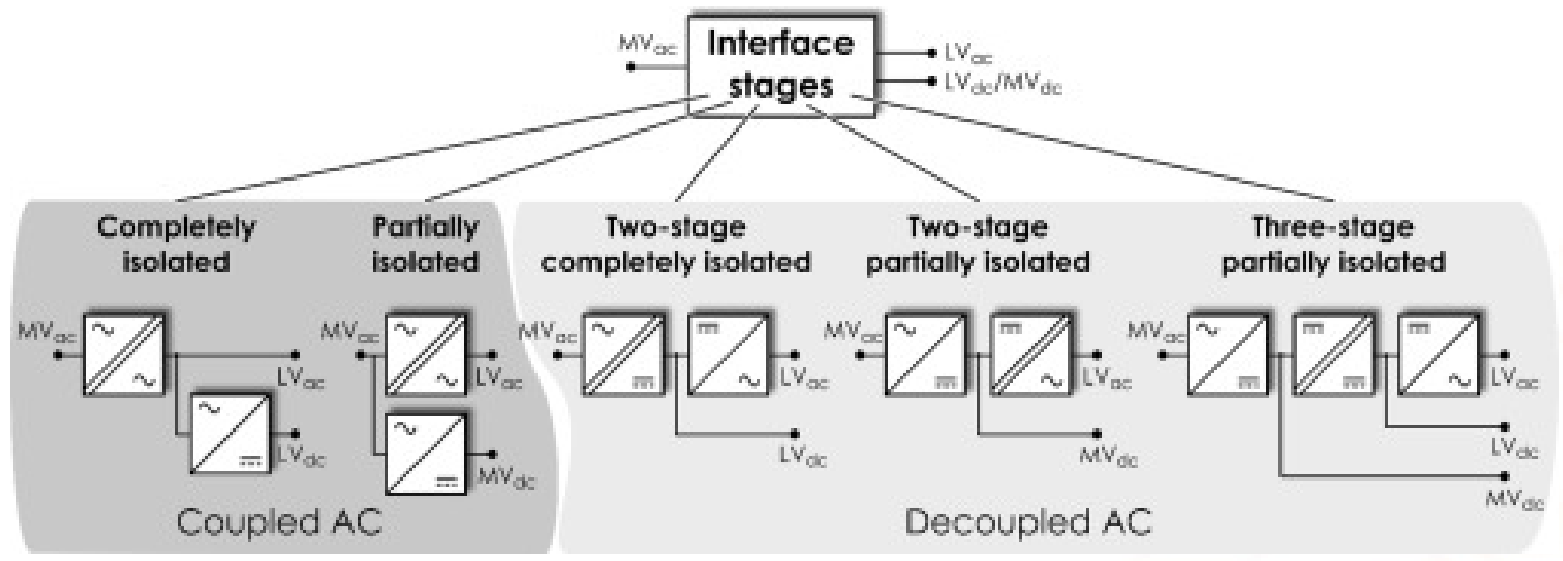

Fig. 3. Hybrid power system interfacing toplogies classification.

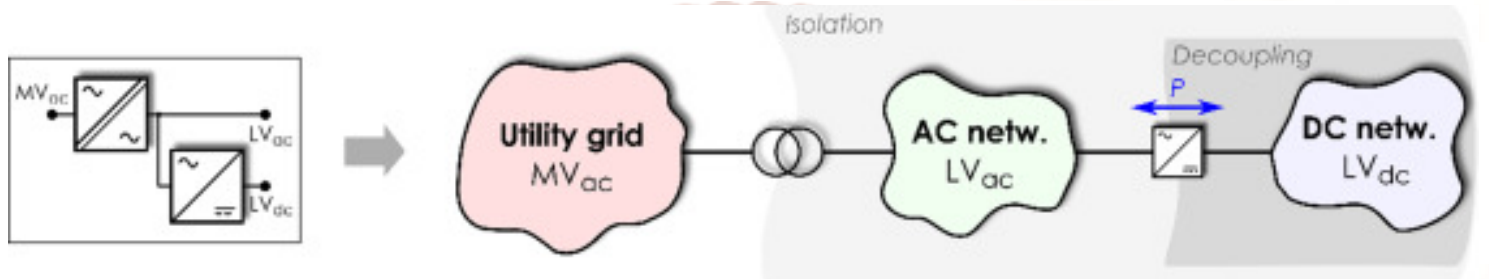

Fig. 4. Coupled ac, completely isolated hybrid microgrid configuration

a) Coupled ac microgrids

The main feature of this configuration is that the ac network is directly connected to the power grid by a transformer. The advantage is that the ac network of the microgrid is fixed by the utility grid in normal operating mode. In addition, the development of a coupled ac microgrid is less expensive than the decoupled one. This is due to the smaller size ac-dc converter that is needed to handle the power flow between the utility grid and the de network.

Two principal methods have been found for the arrangement of conversion stages in coupled ac microgrids. In the first case, as it can be seen in Fig. 3, a transformer is located at the point of connection with the power network. This provides galvanic isolation to the entire microgrid, and reduces the voltage level so that LV ac and dc networks are generated.

b) Decoupled ac microgrids

This type of configuration is gaining interest in the last decade due to the advantages it provides over coupled ones. Firstly, the ac network of the microgrid is decoupled from the utility grid by a dc stage, what provides fault isolation and independent control strategies for both sides of the microgrid (Fig. 4). Moreover, the power flow monitoring and control of the microgrid is inherent of the interface device, which is useful for the coordination with upper level control platforms such as the supervisory control and data acquisition (SCADA) systems managed by electric companies. 
a

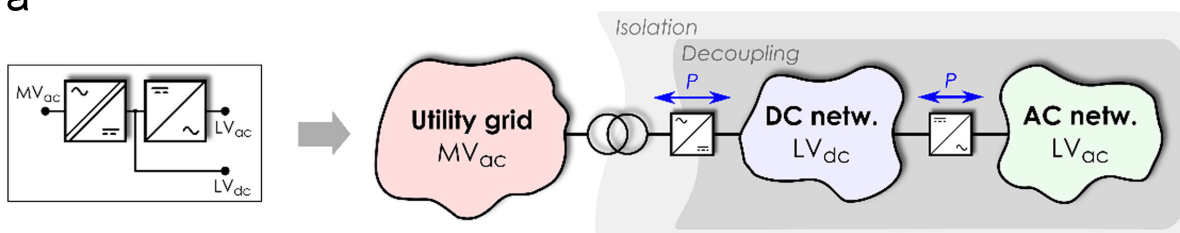

b

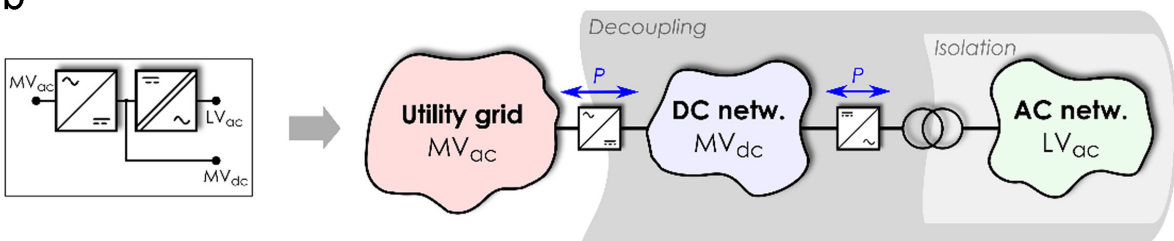

C
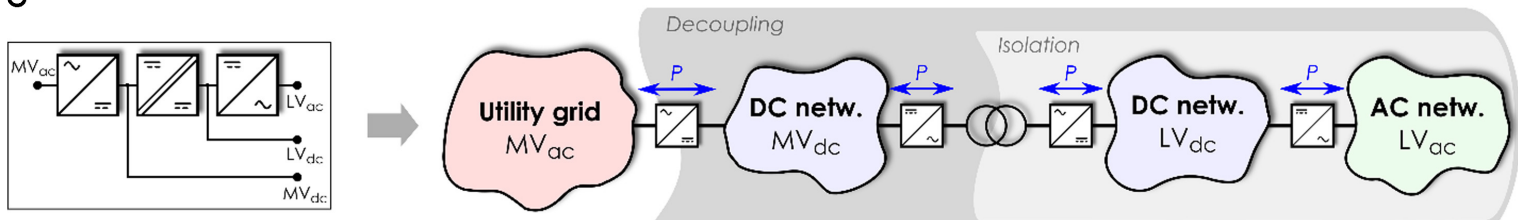

Fig. 4. Hybrid microgrid with decoupled ac network: (a) two-stage completely isolated configuration, (b) twostage partially isolated configuration and (c) three-stage partially isolated configuration.

\section{SIZING TECHNIQUES OF SOLAR-PV-BATTERY BASED SYSTEM}

Renewable energy sources essentially have random behavior and cannot have accurate prediction. Continuous sunny days give abundant PV power because of which the battery banks or hydrogen tanks are underutilized. On the other hand, cloudy days with continuous rain can discharge the batteries and hydrogen storage tanks well beyond the lower discharge limit. Therefore, the number of PV modules to be installed, the size of the FC, battery bank and hydrogen storage tanks need to be calculated carefully considering all extreme weather conditions. Unit sizing and optimization is basically a method of determining the size of the hybrid system components by minimizing the system cost while maintaining system reliability. Optimum resource management in a hybrid generation system is crucial to achieve acceptable cost and reliability level. These design objectives are usually conflicting with one another and thus a reasonable tradeoff between them is desirable. Over sizing the system components will increase the system cost whereas under sizing can lead to failure of power supply. Thus, sufficient care should be taken to design a reliable system at minimum cost.

A classification chart that groups and classifies the various sizing procedures is illustrated in Fig.5. This broad classification is based on the availability and non-availability of weather data, such as irradiance, clearness index and wind speed. When weather data is available, conventional sizing approaches are used and are classified on the basis of concept of energy balance and reliability of supply. However, conventional techniques need long term meteorological data for sizing of PV systems, which may not be available in remote isolated sites. Thus, non-availability of weather data in remote sites has urged the researchers to look into Artificial Intelligence (AI) techniques, such as Artificial Neural Networks (ANN), Fuzzy Logic (FL), Genetic Algorithms (GA) or a hybrid of such techniques. 


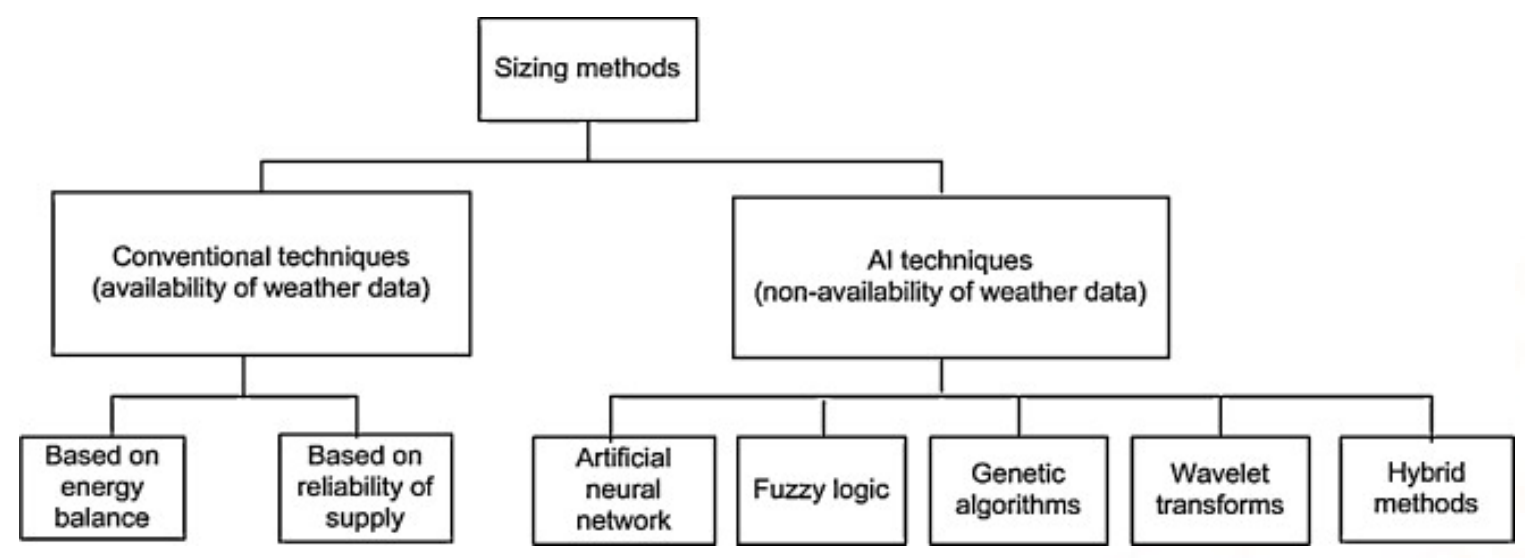

Fig. 5. Classification of hybrid system sizing methods

\section{CONCLUSIONS}

The proposed system is envisioned as an attractive solution towards the integration of DG units in the utility grid. This solution will bring a reduction in the fossil fuel dependency and an increment in the efficiency of the overall electric grid.

Although most of the studies performed in the literature mainly focus on ac and dc microgrids, hybrid ac/dc systems are an interesting solution as they combine the advantages of the previous two configurations. This paper has described and analyzed the most important characteristics regarding the topologies of hybrid microgrids. Different sizing techniques have been reviewed under classification based on availability of weather data.

\section{References}

1) Ramakumar R. Integrated renewable energy systems: power engineering review. IEEE 1995;15(2):10-3.

2) Ramakumar R, Abouzahr I, Ashenay KA. Knowledge-based approach to the design of integrated renewable energy systems. IEEE Trans Energy Convers 1995;10:736-46.

3) Ramakumar R, Shetty PS, Ashenayi K. A linear programming approach to the design of integrated renewable energy systems for developing countries. IEEE Trans Energy Convers 1986;EC$1: 18-24$.

4) Kanase Patil AB, Saini RP, Sharma MP. Integrated renewable energy systems for off grid rural electrification of remote area. Renew Energy 2013;5:1342-9.

5) Ashenayi K, Ramakumar R. IRES a program to design integrated renewable energy systems. Energy 1990;15:1143-52.
6) Ramakumar R, Abouzahr I, Krishnan K, Ashenayi $\mathrm{K}$. Design scenarios for integrated renewable energy systems. IEEE Trans Energy Convers 1995;10: 736-46.

7) Lasseter R, Abbas A, Marnay C, Stevens J, Dagle $\mathrm{J}$, Guttromson R, et al. Integration of distributed energy resources: the CERTS Microgrid Concept California Energy Commission. P500-03-089F; October 2003.

8) Farret FA, Simões MG. Integration of Alternative Sources of Energy. Hoboken, NJ: Wiley; 2006.

9) Sao CK, Lehn PW. A transformerless energy storage system based on a cascade multilevel PWM converter with star configuration. IEEE Trans Ind Appl 2008;44(5):1621-30.

10) Sood PK, Lipo TA, Hansen IG. A versatile power converter for high-frequency link systems. IEEE Trans Power Electron 1988;3(4):383-90.

11) Barton JP, Infield DG. Energy storage and its use with intermittent renewable energy. IEEE Trans Energy Convers 2004;19:441-8.

12) Makansi J, Abboud A. Energy storage. The missing link in the electricity value chain. Saint Louis, USA: Energy Storage Council; 2002.

13) Abbey C, Robinson J, Joós G. Integrating renewable energy sources and storage into isolated diesel generator supplied electric power systems. In: Proceedings of the 13th international power electronics and motion control conference (EPEPEMC); 2008.

14) Chen H, Cong TN, Yang W, Tan C, Li Y, Ding Y. Progress in electrical energy storage system: a critical review. Prog Nat Sci 2009;19:291-312. 
15) Karpinski AP, Makovetski B, Russell SJ, Serenyi JR, Williams DC. Silver-zinc: status of technology and applications. J Power Sources 1999;80:53-60.

16) Moore T, Douglas J. Energy storage, big opportunities on a smaller scale. EPRI J 2006; Spring Issue:16-23.

17) Rahman F, Rehman S, Arif M, Majeed A. Overview of energy storage systems for storing electricity from renewable energy sources in Saudi Arabia. Renew Sustain Energy Rev 2012;16:27483.

18) Rahman F, Skyllas-Kazacos M. Solubility of vanadyl sulfate in concentrated sulfuric acid solutions. J Power Sources 1998;72:105-10.

19) Schainker RB. Executive overview: energy storage options for a sustainable energy future. In:
Proceedings of the Power Engineering Society general meeting, vol. 2: 2004. p. 2309-14.

20) Chauhan A, Saini RP. Statistical analysis of wind speed data using Weibull distribution parameters. In: Proceedings of the 1st International Conference on Non Conventional Energy (ICONCE), vol. 1: 2014. p. 160-3.

21) Khatod DK, Pant V, Sharma J. Analytical approach for well-being assessment of small autonomous power systems with solar and wind energy sources. IEEE Trans Energy Convers 2010;25:535-45.

22) Kanase Patil AB, Saini RP, Sharma MP. Development of IREOM model based on seasonally varying load profile for hilly remote areas of Uttarakhand state in India. Energy 2011;36:5690-702. 